\title{
El tombant del segle XX segons una innocentada de La Vanguardia
}

\author{
XAVIER VALL \\ (Universitat Autònoma de Barcelona. Departament de Filologia Catalana \\ i Centre d'Història de la Ciència $)^{1}$ \\ Francesc.Vall@uab.cat \\ Recibido: marzo de 2013. Aceptado: mayo de 2013
}

\begin{abstract}
Resum: S'estudia el suplement de La Vanguardia del dia dels Innocents de 1889 , que figura ser d'un segle més tard a fi de caricaturar les expectatives de progrés, parodiant especialment Robida, Verne i Fabra, i se n'edita el fragment de la novel-la «La selección infinita», publicat al fulletó sota el pseudònim d'«Hipócrates Darwin».
\end{abstract}

Paraules clau: Literatura catalana d'especulació, periodisme, darwinisme, Stendhal, Émile Souvestre, Albert Robida, Jules Verne, Michel Verne, Émile Driant, José Rúa Figueroa, Antonio Flores, Nil Fabra, Ezequiel Boixet, Josep Coroleu, Narcís Oller, Pompeu Gener, Rafael Puig i Valls, Frederic Rahola, Santiago Rusiñol, Joan Sardà, Miquel Utrillo, Josep Yxart.

\begin{abstract}
Abstrat: We study the supplement of the newspaper La Vanguardia published in 1889 on the occasion of the Holy Innocent's Day (equivalent to April Fool's Day), which was set a century later in order to caricature expectations of progress, parodying especially Robida, Verne and Fabra, and we edit its excerpt of the serial novel «La selección infinita», signed under the pseudonym of «Hippocrates Darwin».
\end{abstract}

Keywords: Catalan literature of speculation, journalism, Darwinism, Stendhal, Émile Souvestre, Albert Robida, Jules Verne, Michel Verne, Émile Driant, José Rúa Figueroa, Antonio Flores, Nil Fabra, Ezequiel Boixet, Josep Coroleu, Narcís Oller, Pompeu Gener, Rafael Puig i Valls, Frederic Rahola, Santiago Rusiñol, Joan Sardà, Miquel Utrillo, Josep Yxart.

El 28 de desembre de 1889 La Vanguardia, renovada sota la direcció de Modesto Sánchez Ortiz (Gaziel 1994: 33-34, Huertas 2006: 25-44), va publicar un suplement datat el mateix dia, però un segle després (Vanguardia 1889). No

1 Aquest article s'inscriu en els projectes HAR2009-12918-C03-02, HAR2012-36204-C02-02 i FFI2011-25051. 
es tractava d'un error, sinó, en consonància amb la celebració del dia dels Innocents, que aquell any queia en dissabte, d'una broma consistent a caricaturar, anònimament, les expectatives de futur. No em consta que aquesta humorada - en part paròdica $i$, fins i tot, autoparòdica- prengués gran rellevància a l'època (ni tan sols n'he trobat cap ressò immediat en la premsa que he consultat) i ha estat negligida pels estudis sobre literatura especulativa hispànica, si bé ja la va evocar Voltes (1964) i s'hi ha referit la bibliografia sobre Rusiñol i Utrillo (Panyella 1981: 35-36, 2009: 24, 271, Casacuberta 1993: 23, 1020-1025, 1997: 25, Laplana 1995: 128-129, Coll 2002: 7-11...2).

El 10 de desembre de 1889 Frederic Rahola va proposar a Rusiñol de prendre part en «dos grandes proyectos» de La Vanguardia: un «cuaderno en el cual irá una lámina de [Josep Lluís] Pellicer con la caricatura de todos nosotros» que es publicaria al final de l'any, que correspon a Apuntes para el resumen del año 1889. Regalo de La Vanguardia a sus sucritores (Vanguardia 1890), i el suplement del dia dels Innocents. Li informa que, en aquest «número extraordinario, que figurará escrito el siglo que viene», hi participaran «todos» (a més de Rahola, «Yxart, Sardà, Oller, Boixet, Coroleu, Puig y Valls», que s'havien reunit el dia anterior i havien acordat, unànimement, de convidar-lo a sumar-s'hi) ${ }^{3}$ :

¿Te parece bien escribir una correspondencia de París como si estuviésemos ya en 1989? o bien ¿te gustaría más hacer una revista de bellas-artes tal y como la imaginas dentro de un siglo? En fin, haz lo que quieras, tú tienes mucho ingenio y, por fuerza, se te ocurrirán mil y mil cosas. La cuestión es que nos mandes algo y pronto y si hay alguna ilustración mucho mejor. (Panyella 1981: 35-36).

Potser va condicionar la col-laboració en aquest suplement la forta epidèmia gripal, que «diezmó» la redacció i els col-laboradors durant el setembre i el gener (Vanguardia 1890: III) .

Com és habitual, el principal dels horitzons del segle XIX era la centúria següent, encara més en acostar-s'hi. Ho il-lustren nombrosos escrits i fins i tot ho remarquen algunes capçaleres, com El Siglo Futuro, de Madrid, o La Lluna. Semi-profeta del Siglo XX i El Siglo XX, de Barcelona.

D'altra banda, existien ja diverses obres d'anticipació, algunes ambientades al nou-cents. Sovint amb un punt d'ironia, s'havia especulat ja força sobre l'evolució de diversos aspectes: la meteorologia, la demografia, l'urbanisme, l'economia, la indústria, l'energia (particularment, l'elèctrica), la il-

2 Ja s'havien parodiat altres publicacions periòdiques. Per exemple, el 1865 es va publicar una carnavalesca Parodia de un Diario de Barcelona, de Avisos y Noticias.

3 La llista recorda força les dels assidus del «Cau Ferrat» (Clarasó 1931: 14, 60-61). Algun participant podria haver estat omès per Rahola o haver-s'hi afegit després, fins i tot també des de París.

La Vanguardia, 1274 (29-12-1889), p. 2, va informar que tres redactors havien contret la malaltia, i 1278 (31-1-1889), p. 2, que el director n'havia sentit els primers símptomes publicada ja la innocentada. 
luminació, els transports (accelerant els terrestres i potenciant els aeris, els subterranis i els submarins) i les comunicacions, la velocitat, la precisió (remarcada sovint amb xifres), les màquines, l'armament, les relacions internacionals o interplanetàries (tendint a l'europeisme o a l'universalisme, per bé que amb la persistència a vegades de l'imperialisme), el poder, l'organització social, el treball, les institucions, l'administració, la justícia, l'ensenyament, les convencions, el rol de les dones, les ciències, les ideologies, la filosofia, la religió, la historiografia, el periodisme, la publicitat, la literatura, els llibres, les arts plàstiques, la música, els espectacles, la moda, l'alimentació, l'hoteleria, el turisme...

Com que molts d'aquests aspectes esdevenen tòpics, no sempre és fàcil destriar-ne les fonts literàries, que es poden entrecreuar, i, a més, cal recordar l'estímul de les utopies, de la situació sociopolítica, de la divulgació científica, de les invencions tecnològiques... Em limitaré a remarcar les coincidències específiques amb alguns dels referents més destacats que podien tenir presents els col-laboradors de La Vanguardia (no necessàriament cadascú els mateixos).

Sense remuntar-nos a abans del segle XIX i no anant més enllà de 1889 , en primer lloc, destacaria la novel-la Le monde tel qu'il sera (1845-1846), d'Émile Souvestre (s. a.), ambientada el 3000, tot i ser encara força rudimentària. Molt més avançada és ja Le vingtième siècle (1883), d'Albert Robida, amb illustracions de l'autor, que, situada el 1952, s'emmarca en una trilogia que van continuar La guerre au vingtième siècle (concebuda el 1869 i editada el 1887; Beraldi 1916) i, ja posterior a 1889, Le vingtième siècle. La vie électrique. La producció de Robida connecta amb la de Verne (Lacaze 1980), que gaudeix d'una considerable presència a terres catalanes (Munné-Jordà 2005, Pinyol 2005), també en La Vanguardia.

Entre moltes altres especulacions vernianes sobre el futur, destaquen Paris au XXe siècle, escrita el 1863, però inèdita fins al 1994 (Verne 1995), Une ville idéale, ambientada l'any 2000 a Amiens, publicada en vida de l'autor tan sols el 1875 en les memòries de l'Académie des Sciences, Belles-Lettres et Arts d'aquesta ciutat, on l'havia llegit el mateix any, i com a opuscle (Verne $s . a$.), i In the Year 2889, editada en anglès i amb il.lustracions de George Roux al núm. 6 en la revista novaiorquesa The Forum, que comprèn del setembre de 1888 al febrer de 1889, pp. 662-677 (Verne 2011, 2004) . La signatura «M. Verne» es va interpretar com a «Monsieur» 0 «Mister Verne» (encara que en anglès seria més usual l'abreviació «Mr.»), identificant, òbviament, l'autor amb Jules. Podria tractar-se, però, d'una ambigüitat calculada, perquè ell mateix, en una carta del 29 de gener del 1889 a Jules Hetzel, el seu editor, atribuïa l'obra, una mica confusament, al seu únic fill, Michel, si bé, igual que ell, no tenia prou coneixements d'anglès per redactar-la en aquesta llengua. El fill, que s'ha conjeturat que en va redactar diverses obres, va participar en l'edició pòstuma de la

5 Extrec les dades relatives a aquestes obres de diversos estudis sobre Jules Verne. Pel que fa a les qüestions d'autoria, veg. en particular Arthur B. Evans (1995). 
narració dins Hier et demain (1905). Més enllà de la lectura de Jules Verne a l'esmentada acadèmia el 1890, l'obra de seguida es degué difondre força per Europa $^{6}$.

Quant als precedents hispànics de caràcter més estrictament anticipatiu, tot i predominar-hi la sàtira (amb al-lusions a les utopies i entroncant amb el costumisme), sobresurten les narracions «Madrid en el año 2851. Nuevo porvenir del mundo», de José Rúa Figueroa (1851, Jobit 1936: 49, que la interpreta com una crítica al krausismo, Simón 1946: 232, Roas 2000: 722, GICES 2008), i Ayer, hoy y mañana, o la fe, el vapor, la electricidad. Cuadros sociales de 1800, 1850 y 1899. Dibujados a la pluma (1863 [1853 1a ed.], Saiz 1988: 19-21, Mainer 1988: 151-152, Santiáñez-Tió 1995: 22, Roas 2000: 722), de l'alacantí Antonio Flores. De totes maneres, el 1889 no tan sols havia transcorregut ja molt de temps des de la publicació d'aquestes obres, sinó que gairebé era el futur de la segona, situada només una dècada després, per la prudència de no gosar anar gaire enllà, a diferència de L'An 2440. Rêve s'il en fut jamais, de Louis-Sébastien Mercier (1771), i del ja esmentat Le monde tel qu'il sera, de Souvestre (Flores 1863: IX).

Un antecedent molt més pròxim és el periodista i narrador Nil Fabra (n'abunden les referències en diversos estudis) i, en particular, «El desastre de Inglaterra en 1910», «Cuatro siglos de buen gobierno» $\mathrm{i}$ «Un viaje a la República Argentina en 2003», publicades, respectivament, en La Ilustración Española y Americana (1883a, 1883b, 1889), la darrera pocs mesos abans de la innocentada, el 8 de juny. En la primera narració, s'aconsegueix el viatge en el temps merament datant l'article el mateix dia d'anys després, com en el suplement de La Vanguardia, procediment menys imaginatiu que altres, però simple, eficaç i versemblant ${ }^{7}$.

Centrant-nos en aquest diari, a més de referir-se al segle $\mathrm{XX}$ diversos articles, Josep Yxart (1888) ja hi havia publicat, com si fos «de un periódico futuro», la narració «Un crimen en 1988», encapçalada per una citació de Lope de Vega (no precisa que és extreta de l' «Égloga a Claudio»): «Quien mira lo pasado, el porvenir advierte». Certament, la fictícia crònica és premonitòria de l'ús del delicte com a espectacle pels mitjans de comunicació: un periodista entre-

6 Per exemple, l'1-4-1889 la reprodueix El Isleño, de Palma de Mallorca, a primera plana amb el títol d' «El periodismo en 2889», ponderant que, entre «los sueños de J. Verne», «ninguno hay cuya realización tenga para la prensa la importancia d'aquest, del «que dan cuenta las revistas extranjeras» (Verne 1889: 1).

7 Similarment, en Rúa 1851, permet la transició temporal la data del diari que llegeix el protagonista. Entre altres narracions discròniques anteriors a 1889 destaquen també: «La vida en el año 6000», de Santiago Ramón y Cajal, que es va editar ja pòstumament, «Un manuscrit de sabi o de boix» (1880), de Valentí Almirall, «Cuento futuro» (1886), de Leopoldo Alas, i el vitage al passat de l' «Anacronópete» (1887), d'Enrique Gaspar (entre abundants referències a aquesta obra, veg. Augusto Uribe 2002, Camprubí 2011). Emili Guanyavents havia situat el seu poema «Demà» al segle XXI (Vall 2005: 29). Pel que fa la datació de la peça l'Any 13000, de Miquel Figuerola i Aldrofeu, puc precisar que, en La Esquella de la Torratxa, 735 (10-2-1893), p. 95, se n'anuncia l'aparició la setmana següent. A més, en diverses obres utòpiques o distòpiques es projecten també especulacions futures. 
vista a la «Cárcel Maravilla» un assassí que ven les seves peripècies a la premsa, fins que acaba linxat.

El primer article del suplement, «De Europa a la América del Sud» (p. [5], paginació que continua la de la resta del diari), és signat per «Fed. Alohar», anagrama de Frederic Rahola usat ja en La Bandera Catalana el 1875. Coincideix amb Fabra 1889 en el vertiginós viatge amb tren elèctric i per túnel submarí fins a l'Àfrica — passant per Gibraltar, recuperat per l'Estat espanyol (el 1910 en Fabra 1883a, 1889: 335) — i d'aquest continent a Brasil, amb un transatlàntic també elèctric (submergible en Fabra 1889: 338$)^{8}$. Pel que fa a la tecnologia armamentista, Rahola imagina «resortes mecánicos del gobierno», «eléctricos y magnéticos», «para producir en los súbditos los fenómenos hipnóticos necesarios en caso de conflicto» ${ }^{9}$. Ho fa a propòsit de Libèria, país fundat pels esclaus dels Estats Units alliberats que estaria dominat per una oligarquia de blancs, circumstància que, donant validesa a reprovables prejudicis racistes, provaria la incapacitat dels negres per a l'autogovern. Almenys, Rahola qualifica d'«horrible» l'antic mercat d'esclaus a Timbuctú, convertida en «la ciudad más industrial de África», que exportaria, entre altres productes, «alcohol amílico» a Alemanya, «vengando así al África de la intoxicación de que fue objeto en el pasado siglo» (en Robida 1883, s'esmenta vàries vegades Timbuctú, de la qual partiria un «tube»). Val a ressaltar també que a Fes, el nou Mònaco, el casino inclouria la borsa.

El següent article, «A través de un siglo» (pp. 5-6), fa balanç de l'evolució, sobretot urbanística de Barcelona, «la Ville Lumière [París] de España», que el 1989 tindria més d'un milió d'habitants, xifra que, encara que és molt inferior a la real, vol connotar un gran creixement demogràfic ${ }^{10}$. La signatura, «Rafael de Puig», coincideix amb la del col-laborador habitual Rafael Puig i Valls, tot i intercalar-se entre el nom i el cognom la preposició «de», que potencia l'associació del llinatge amb el nom comú, suggerint la professió d'aquest autor, enginyer de monts, i conjuminant amb les referències a Montjuïc (convertit, després d'instal-lar-hi un nou cementiri —no sense discussions sobre si no seria

8 En canvi, el penyal seguiria essent britànic en Robida 1883, en què abunden viatges a l'Àfrica i a Amèrica del Sud, aerostàtics, navals i mitjançant «tubes» subterranis o subquàtics, com l'«Express-Madrid-Gibraltar-Tanger» (il-lustrat a les pàgines 176 i 177) i un de transatlàntic. Verne 2004 hi coincideix tant pel que fa a l'estatus de Gibraltar (p. 13) com als tubs, que portarien de Nova York a París en 295 minuts, superant els 1000 km/h dels aeròstats (p. 20). Rahola concep, a més, túnels subaquàtics al Canal de la Mànega (com la també antibritànica Fabra 1883a), vençudes les reticències dels anglesos, «tan celosos de sus costumbres, hipócritamente puritanas», i entre Itàlia i Sicília i d'aquesta illa a Tunísia. A l'època se'n van projectar diversos. La Vanguardia, 910 (6-6-1889), p. 1, havia ponderat que un vapor que havia travessat l'Atlàntic en «tan solo» 5 dies, 23 hores i 7 minuts feia ja menys inversemblants els 9 dies de Le tour du monde en quatre-vingts jours, de Verne.

9 L'anticipació bèl-lica esdevé un subgènere força conreat. A més del referent de Robida (1883: passim, Beraldi 1916) i de diverses narracions de Fabra, cal destacar les obres del militar Émile Driant. La Vanguardia, 597 (13-12-1888), p. 2, havia donat notícia de la publicació de La guerre future [La guerre du demain], d'aquest darrer escriptor, obra «al estilo de Julio Verne».

10 En Verne 2004: 2, les ciutats arriben a vegades als 10 milions d'habitants. 
millor la incineració- i aplanar-lo fins a 100 metres d'alçada, en un «Balcón del Mediterráneo») i al Tibidabo, al-ludint al projecte de la Diputació d'installar-hi un observatori, ocurrència que supera les del Quixot i les de Tartarin de Tarascon, el conegut personatge de Daudet. Entre altres reformes infraestructurals de Barcelona, s'hi hauria millorat el clavegueram, portat l'aigua de la Noguera Pallaresa i conduït l'electricitat obtinguda de salts i del mar. Amb tot, més que el progrés material, es valora el «adelanto moral», en contrast amb la corrupció vuitcentista, particularment de l'administració espanyola.

Santiago Rusiñol, a més de ser esmentat en una de les «Notas locales» com a besavi d'un pintor (p. 8), portant a terme la proposta de Rahola, hi signa i illustra la crònica artística «Salón 1989», datada a Montmartre el mateix dia que el suplement (pp. 6-7, editada en Casacuberta 1993: 1020-1025; veg. també, sobre l'humorisme de l'autor, Casacuberta 1996, i, pel que fa a la relació de la literatura catalana amb París, entre altres escrits sobre el tema, Casacuberta 2002). Comença remarcant que se celebra a l'hivern buscant la fredor de la crítica, a diferència de la predilecció per la primavera de l'efusiu idealisme vuitcentista. A la lluïda inauguració — amb l'assistència del president, però sense discurs — arriba una gernació, entre la qual no falten dignataris i homes il-lustres d'arreu del món, gràcies a diversos mitjans de transport («trenes eléctricos», «globos», «ómnibus automáticos», «bicicletas funiculares», «aéreos buques», «vagones motores lanzados al vuelo por el aire comprimido», «tubos lanzapasajeros» subterranis, «Perales», que remunten el Sena amb «los moradores lacustres que viven reposados en la profundidad de los mares»...) $)^{11}$.

A la «pincrópolis» d'un palau amb façana de níquel, «entre las cuatro torres soberbias de productos inorgánicos y la cúpula cuadrada de dorado carbón de piedra», s'apleguen «ochenta mil cuadros y treinta mil estatuas» - tot i que se n'han rebutjat o se n'han perdut-, producte d'una «pintomanía» de «proporciones alarmantes». Es procura pal-liar amb destruccions massives, sense arribar, però, a l'extrem d' «algunas ciudades españolas, donde, con muy buen acuerdo [ironitza], no forman ningún museo ni compran ninguna obra de arte, logrando con esta medida prudente y económica alejar [a] los artistas de su patria y librarse de este morfinismo estético que ha de acabar con el sentido común y que aparta el entendimiento humano de los senderos utilitarios y aleja la juventud del sano positivismo, para lanzarla en cuerpo y alma en busca de ideales que para nada sirven al desarrollo da las fuerzas físicas ni al desenvolvimiento de la agricultura».

La «nueva exposición camina por senderos científicos (menos mal) y en los diversos grupos y escuelas recién nacidas se ve el afán de los artistas de hermanar las matemáticas y la física con la reproducción de la naturaleza, tendencia

11 Com en altres articles del suplement, l'actualitat d'Isaac Peral relega Monturiol, que ni s'hi esmenta. Convé tenir present, entre altres possibles referents, Vingt mille lieues sous les mers, de J. Verne, novel-la que, mentre que a França no es va acabar de publicar fins al 1870, es va editar en versió castellana íntegra de Vicente Guimerà per l'Establecimento Tipográfico de F. Rey y C. ${ }^{a}$ de Madrid amb data de 1869. En Robida 1883: passim i Verne 2004: 16, s'imaginen també ciutats submarines. 
que nos pone en guardia, pues, como hemos dicho al empezar, desconfiamos siempre de estas simbólicas hermandades», advertiment que, tenint presents altres comentaris de Rusiñol sobre la relació de l'art i la ciència, no sembla ja irònic ${ }^{12}$. Entre les noves escoles, esmenta l'«ondulatoria», els pintors de la qual «reproducen en sus lienzos la vibración de las ondas luminosas y envuelven las figuras y el paisaje en sendas líneas transversales, que, si bien impiden ver el cuadro a la primera mirada, sobretodo para los que no usan verdes anteojos», produeixen una «sensación agradable en la retina del espectador», sense alterar-li ni la digestió ni el sistema nerviós; la «prismática», els seguidors de la qual, «teniendo en cuenta la descomposición de los colores del arco iris, dan atmósfera a sus cuadros», i la «colorista», que pinta amb «el polvo disuelto y hábilmente amasado que destilan las brillantes y verdes cantáridas, con los sutiles reflejos de los pájaros moscas y pavos reales, y con los colores enteros que visten las mariposas todos los días del año», tendència predilecta de les dones, que veuen «en la fugacidad de tonos cierta analogía con su modo de pensar y sentir el arte y otras cosas más efímeras de la existencia».

La pintura vuitcentista té ja un interès purament arqueològic, però no desaprofita l'oportunitat de criticar-la jugant amb la perspectiva futura. Així, «Dagnan-Bonberet [Bouveret]» $\mathrm{i}$ «Bastien-Lepage», que, «creyeron ser naturalistas en su época», «resultan de idealismo escolástico». Entre molts quadres enviats o telegrafiats des de diferents països, hi ha pintures espanyoles de caràcter històric: a més de la batalla de Guadalete, evoquen les cruentes morts de toreros a la plaça de braus de Madrid, ciutat destruïda al començament del segle per «una invasión de políticos que en pocos años dejó sin alimentos a todo el vecindario», i una representación de «la conversión de la deuda» en forma de «fatídico cementerio». No entra en l'escultura pretextant que l'augment de la temperatura de l'habitació fins a $14^{\circ} \mathrm{C}$ li impedeix mantenir una gèlida imparcialitat.

«M[iquel]. Utrillo», polifacètic enginyer amic seu, signa, com solia (Sierra 2012), una crònica «Desde París», també a Montmartre i acabada el mateix dia, a «a 87 metros sobre el nivel medio del mar, 8 grados centígrado[s] bajo cero, y con 72 pulsaciones por minuto en el sistema circulatorio» (pp. 7-8). La transmet per «fonoteléfono especial» a les «23 horas 85 minutos 99 segundos» (en un sistema horari que no seria, doncs, sexagesimal) i és rebuda amb 2 minuts i 20 segons de retard. Com que en el nom de l'artefacte coincideixen el prefix i el sufix, si no es tracta d'una redundància burlesca, devia voler indicar-se que l'article hauria estat «fonotelegrafiado», com el de Rusiñol ${ }^{13}$. Encapçala la crònica un retrat pintat per ell d'Utrillo escrivint amb aquest sistema l'article i el tanca un gravat signat amb un conegut pseudònim d'aquest, «Lilé». Els altres dibuixos són d'Andreu Solà i Vidal (Panyella 1981: 36, Coll 2002: 9-10), que

12 Més enllà de les concepcions artístiques de possibles fonts (Souvestre: 225-245, Robida 1883: 48-54, 260-266, Verne 2004: 16, que imaginen ja una pintura creada amb procediments tecnològics, sovint fotogràfica i reproduïda en sèrie), Rusiñol hi projecta les seves.

13 Robida (1883: passim) s'imagina també l'híbrid «téléphonograph» i, en Fabra 1889: 335, un fonògraf connectat a «la red universal telefónica» actua de «Noticiero parlante» $\mathrm{i}$ un megàfon reprodueix una òpera mentre es representa al Teatre Apol-lo de Roma, a més d'haver-hi llibres fonogràfics. Sobre la circulació del fonògraf, veg. Vall 2012. 
va il.lustrar altres articles d'Utrillo en aquest diari (Fontbona 2003: 19; sobre aquest artista, veg. també Teruel 2003: 59-60). Poc després de la celebració de l'Exposició Universal en aquella ciutat (Giné 2010, Sierra 2012), Utrillo hi imagina diverses innovacions futures.

En primer lloc, dóna notícia del «panographe» (terme ja aplicat a altres invencions), un diari que - a més de tenir 24 edicions al dia, com tots- està «cromofotografiado en una sola hoja de cuatro metros cuadrados, formada por un tejido elástico que se contrae o se dilata según la voluntad del lector, por medio de las vibraciones emitidas por la retina $»^{14}$. Les seves seccions són les habituals, més o menys evolucionades i caricaturades: la informació borsària disposa d'una «guia de las operaciones» «según el cálculo de probabilidades»; els horaris dels mitjans de transport corresponen a «hidrocarriles, aereotrenes, Perales, paquetes reostáticos [«aerostáticos», si es tractés d'una errata]»; els «escándalos» literaris ocasionen «150 desafíos filosóficos»...

Trencant el monopoli de la Sociedad General de Alimentación en el subministrament de menjar mitjançant «tubos de salsa compromida» (a l'antiga plaça de la Borsa, aleshores anomenada «del Becerro de Oro»), s'ha obert un restaurant en què «los clientes saborean toda clase de manjares con el excitador eléctriconervioso y se nutren suficientemente con los gránulos concentrados» ${ }^{15}$.

La memoria de l'oficina d'estadística de Montmartre xifra en 85.250 els «matrimonios condicionales», pocs de perpetus i alguns per un lapse molt breu. Un enllaç va ser dissolt pel «triple tribunal», compost de tres instàncies classificades segons la capacitat cranial dels membres, perquè la núvia tenia 18 anys i el nuvi 65, el qual va ser condemnat a «trescientas consideraciones filosóficas sobre las obras de Ponson du Terrail [creador del personatge de Rocambole, que ha donat lloc a l'adjectiu rocambolesc], pena menos atroz que

14 Souvestre s. a.: 277 havia concebut un diari anomenat «Le Grand Pan», l'únic exemplar del qual, elaborat en una immensa redacció automatitzada, s'imprimia en un paper continu que, per un sistema de rodets, anava passant per totes les llars a un ritme uniforme. A diferència també del panographe, sostenia alternativament totes les opinions, si bé marcant cada tendència amb un color.

15 Entre altres referències a l'automatització hotelera en narracions anticipatives, destaca la presència de l'alimentació científica i la canalització dels aliments en Robida 1883: 77-88, i Verne 2004: 5, 14. Rusiñol reprendrà la idea de la conducció del menjar en la narració «El somni de l'inventor», recollida a Aucells de fang (editat a l'inici del 1905 per la Tipografia de L'Avenç). Va ser adaptada com a monòleg amb el títol de L'escudellòmetro, publicat per aquesta editorial el mateix any i representat al Romea el 6 de març (Casacuberta 1993: 722, 1997: 414). Ambdues versions es recullen dins les Obres completes (S. Rusiñol 1973: I, 403-405, 1976: II, 182-183) i la teatral, a més, en S. Rusiñol 2011: 89-101 i Martínez-Gil 2005: 417-419). Sempronio va suggerir que l'obra podria inspirar-se en les utopies del pedagog Rufino Carpena Montesinos (MunnéJordà 1985: 27, 2002: 80, Roig 2012: 41), encara que les publicacions seves més cèlebres sobre el tema són posteriors. Quant a l'afecció de Rusiñol a l'escudella, veg. M. Rusiñol (1968: 30-31). El terme escudellòmetre ha esdevingut d'ús comú, com recull el Diccionari de la Llengua d'Enciclopèdia Catalana, per referir-se a un 'estri d'alumini, usat pels excursionistes, consistent en dos o més recipients que encaixen entre ells i que porta incorporat un fogonet d'esperit de vi per a coure o escalfar menjar'. 
la que señala la ley española en igual caso, puesto que esta exige dos mil prólogos de canutillo a las versiones latinas de [Francisco] Com[m]elerán y Gómez». En la memòria, consten també «las cantidades gastadas» en «la calefacción de las calles y plazas, la producción de oxígeno para purificar el aire» y «el carbonato de potasa empleado para la absorción del ácido carbónico y del protóxido de nitrógeno o gas hilarante de los antiguos, usado en los días [de] mal humor general».

Pel que fa al Saló remet a la crònica de Rusiñol, si bé hi afegeix, entre altres dades, que «las palabras empleadas por los artistas hablando mal unos de otros el día de la cristalización de las telas equivale a 2.000 discursos de Demóstenes, 37.000 epístolas de San Pablo a los Corintios y raíz de dos B 4 [de] los discursos de los oradores españoles del siglo XIX». Quant al teatre, destaca l'estrena amb «teléfono-traductor», a la «Fábrica Central de Dramas, situada en la plaza del Teatro Políglota, frente a la avenida de la Melodía Trascendental», de «la obra en tres fases y cincuenta puntos de vista» Los amores mortales en la escala zoológica, basada «en los datos suministrados por los archivos de la Academia de Ciencias y las notas personales del gran naturalista Darwater» ${ }^{16}$. Ha de tractar-se de la broma fàcil de substituir l'acabament «win» —que suggereix $v i-$ per la paraula anglesa equivalent a aigua. Les obres de Wagner, si bé encara s'escolten, fonogràficament, han esdevingut «triviales» al costat del «compositor californiano Carretero». Per mitjà del «teléfoto o teléfono de la visión y del telefonógrafo», «en el vasto coliseo de las Actualidades palpitantes», es representen «los sucesos del día» poc després d'haver passat (des de la festa de la «Nueva Atlántida»a les agonies d'homes il·lustres) ${ }^{17}$.

Després de donar notícia del «bacillus de la pobreza» i dels seus tractaments, acaba augurant nous avenços molt superiors si no es produeix una alteració climàtica del planeta, que no seria l'escalfament —encara que les regions antàrtiques han estat desgelades per la Sociedad de Estufas Sísmicas, que tenia el projecte de dessecar l'estret de Bering per verificar si van entrar per allí els pobladors d'Amèrica一, sinó l'«enfriamiento progresivo», a causa de la «precesión de los equinoccios».

Aquesta crònica pot fer pensar en les notícies que apareixen en algunes fonts, com els avisos del «gran árbol de la publicidad», que, empeltat pel perio-

16 En Robida 1883: 114-116, s'imaginen representacions teatrals simultànies en diverses llengües.

17 A l'acabament dels setanta, amb l'estímul del telèfon i altres invents, es va especular sobre aparells que transmetessin també imatges. Théodore du Moncel defensava les possibilitats de la invenció del «téléphote» en Le Microphone, le radiophone et le phonographe (1882: 109, 199-319). En Robida 1883, s'anomena «téléphonoscope», que, fins i tot, pot ser de butxaca (1883: passim). El terme «téléphote» reapareix en Verne 2004: 2, 5, juntament amb el «phonotelephote», 7, amb els "phototélegrammes» interplanetaris, 14-15 i 20-21, en Le Château des Carpathes (1892), del mateix autor, i en Fabra 1889, que, en «En el planeta Marte» (1890), el denominarà telefoteidoscopio. Lasa, J. F. (1996) s'ha referit a la presència en Robida i Verne d'aquestes invencions, que relaciona amb la televisió, però que, actualment, a més, es poden associar a les videoconferències. 
disme, produeix a vegades més aviat gazetillas (Flores 1863: 47-76) o el «noticiero parlante» de Fabra 1889: 335, però es tracta d'un recurs obvi, i més parodiant un diari.

S'utilitza també en les «Notas locales» (p. 8) sobre diversos aspectes: amb al-lusions a Manuel Girona i bromes sobre els espiritistes, la inauguració del flamant nou Ateneu Barcelonès, que contrasta amb la decrepitud de l'Acadèmia de Bones Lletres i altres institucions semblants; les polèmiques entre els diaris El Diluvio i l'imaginari antagonista conservador El Arca de Noé; la troballa de monedes d'Alfons XIII (nascut el 1886) en aixecar el terra de la Rambla per pavimentar-la amb suro comprimit, en al-lusió al preu elevat d'uns «tarugos» col-locats el 1889, criticats per la premsa; la persistència, generació rere generació, de la saga de Rius i Taulet a l'Ajuntament de Barcelona, que encara no ha acabat de pagar les despeses de l'Exposició Universal de 1888; el retard del tren de València, que impedeix l'enllaç amb el globus que porta a Nàpols; els viatges multitudinaris (7.483 passatgers) en un submarí anomenat Isaac Peral; la inversió de rols entre homes i dones (la defensora d'una noia acusada de raptar un cadet ha de ser substituïda per una altra perquè dóna a llum en el judici) ${ }^{18}$; la simplificació de la burocràcia judicial; les invencions d'un l'enginyer industrial -inspirat probablement en Salvador Mañach Trias, perquè se l'anomena amb aquest primer cognom-, entre les quals «el vista de aduanas automático o incorruptible», «el cajero modelo», «el cochero de plaza mecánico»..., culminades per la «nodriza automática» ${ }^{19}$; la inoculació per l'Institut Ferran (anomenat així en record del Dr. Jaume Ferran i Clua) del virus «antichanchúlico» ${ }^{20}$; els reiterats divorcis de l'aristocràcia; el debat en el «consejo anfictiónico» de la Unió Europea (a Viena, però a punt de traslladar-se a La Haia) sobre la convalidació dels títols professionals entre les seves nacions, alguna encara monàrquica -anticipant l'Espai Europeu d'Educació Superior, sense arribar a imaginar-ne, però, aspectes inconcebibles-, després d'haver acordat la reducció de la despesa militar per dedicar els diners a hospitals per a obrers invàlids, com el construït entre Sarrià i les Corts; la controvèrsia sobre si unes ruïnes, que han de referir-se al Palau Güell, són obra del XIX, com defensa «Gaudy», a partir de l'arxiu familiar —al-ludint-se, òbviament, Antoni Gaudí—, i nega una comissió d'acadèmics, entre els quals Sampere i Rogent (cognoms que fan pensar en Salvador Sanpere i Miquel i Elies Rogent), que les considera babilòniques.

Segueixen unes «Notas regionales» (p. 8), en què, entroncant, distanciadament, amb l'humorisme pitarresc, es bromeja sobre la inauguració a «la importante villa de Vimbodí», amb l'assistència de més de 25.000 persones, d'una estàtua de cartó-pedra, obra de Venancio Sugrañes (al-ludint segurament a Venanci Vallmitjana, però potser jugant també amb el segon cognom de Claudio Lorenzale, mort el 31 de març de 1889) que representava a Carles Altadill de

18 En Robida 1883: 98-108, les advocades s'encarreguen dels processos criminals per la seva efusió sentimental, combinant-se així l'ascensió de la dona amb estereotips masclistes.

19 Aquest invent es troba ja en Flores 1863: 71-72.

20 La corrupció persisteix en diverses obres. En Robida 1883: 116-127, s'imagina els diputats escortats tothora per diversos vigilants, a fi d'evitar-la. 
Gandul (el segon cognom s'ha inventat en al-lusió al seu sobrenom i al títol de la seva comèdia més cèlebre), difunt des de 1878, en posició jacent ${ }^{21}$. En una vetllada literària d'homenatge a aquest escriptor a l'Ateneo Políglota y Terapéutico d'aquesta ciutat, es llegeix el poema «La ñoña», de Rufina Estornell ${ }^{22}$, i un treball de l'erudit «Serafín Barraquetas» defensant l'atribució de Judes —en contra de l'opinó que era obra de «Pitarra y Soler», «un poeta que por los años de 1870-80 gozó de gran favor»—e Altadill, que n'hauria interpretat el paper de protagonista, mentre que el de Magdalena l'hauria representat Matilde Díez, dona de l'actor Julián Romea. Judas de Keriot, de Frederic Soler, Pitarra, s'havia estrenat el 15 d'abril de 1889 al Romea.

Entre l'article de Rusiñol i el de Utrillo (p. 7), potser perquè era obra d'algun d'ells o simplement per raons de composició, una altra nota, amb el títol d' «El nuevo teatro de la ópera», havia fet la crònica de la inauguració d'aquest espectacular local construït a Barcelona al bell mig de la plaça de Catalunya, amb quatre façanes i un pati interior porticat obert a la circulació. L'obra escollida va ser Cristobal Colón, del compositor Foraster, que en preparava una altra sobre Bernat de Cabrera, temes tòpics. Durant la representació, en la penombra de l'escena nocturna del ball de les índies, van resplendir entre el públic, com a lluernes, els llumets elèctrics que les dames soldrien portar al pentinat.

En el fons de Narcís Oller de l'Arxiu Històric de la Ciutat de Barcelona, hi ha una carpeta improvisada doblegant el dors d'un formulari judicial imprès, en què al centre es destaca el seu nom, en castellà, i el primer cognom estampats en majúscules (5D.53-8/C11-1). S'hi ha retolat en negre «Número de Inocentes de La Vanguardia» i un interrogant en blau, que és probable que sigui més recent.

Dins, s'ha conservat un manuscrit autògraf titulat «Antiguallas». És escrit horitzontalment sobre la cara en blanc de quartilles obtingudes tallant la part superior de setze exemplars d'uns comptes impresos de l'Associació d'Autors Dramàtics Catalans. Al final s'ha afegit, també a ploma, però amb traç més fi, la signatura amb les inicials de Narcís Oller i, en llapis, la indicació «destinat a un n. ${ }^{\circ}$ de La Vanguardia extraordinari de Cap d'Any i d'Ignocents, que em sembla que no es va publicar» (f. 16r).

A l'anvers d'aquest full, que és l'únic escrit per les dues cares, es llegeix, amb la mateixa lletra, però verticalment, una nota en què es defensa que, per raons científiques, «los 4 dinamos-soles» han de «fulgurar» a 1.000 metres, en lloc de fer-ho a 400 (altura a la qual, essent articulats, podrien davallar en dies de boira). Es proposa contra el parer del «consejo metropolitano de esta ciudad», les obres del qual es caracteritzen per «la mezquindad de miras». Així, es projecten en el futur les crítiques per la manca d'ambició urbanística i, en par-

21 Vimbodí era conegut i visitat sobretot per ser prop de Poblet. Així la primavera d'aquell any havia estat per aquelles terres Rusiñol en la campanya pictòrica entorn d'aquest monestir (Panyella 2012).

22 El nom de la poetessa no sembla al-ludir almenys cap de les més conegudes (veg. Pinyol 2006). 
ticular, per la pobra il-luminació. Es compara els detractors amb els que al segle anterior es van oposar a la Torre Eiffel (construïda per a l'Exposició Universal de 1889).

Fora de la carpeta original, encara que podria haver-hi estat a dins, es troba un altre manuscrit (5D.53-8/C11-2), signat també amb les inicials i titulat «El Gran Hôtel [escrit a la francesa] de la muerte». Una societat anònima projectaria la creació d'un centre a la falda de Montjuïc, prop del cementiri, en què, al preu de 100 pessetes, després de gaudir de les màximes comoditats com a màxim durant un dia, es moriria de forma agradable, suscitant l'enveja, fins i tot, dels immortals. Aquesta nota macabre coincideix amb altres del suplement, particularment amb les referències a l'esmentada muntanya d'«A través de un siglo».

Centrant-nos en «Antiguallas», potser aquest escrit, més elaborat, ha restat inèdit per la dura crítica envers el Diario de Barcelona, «publicación curiosísima por su forma, por su fondo, por su duración e influencia», que es pot consultar «al salón 33», «estante 2257», de «la Gran Biblioteca Central», accedint per la «puerta 27, lado norte» a aquest gran edifici, on, fins i tot, es pot dinar, per «10 centenas», al Restaurant núm. 12, equipat de telèfon i de «fotovelón-telégrafo» (ff. 1-8r, 16r $)^{23}$. Aquest aparell ha de ser semblant a altres artefactes cinematogràfics esmentats, a vegades també transmissors, igual que l'«electroscopo», amb la rapidesa del qual es compara el pas per la imaginació del futur lector de la premsa vuitcentista de «cuadros pintorescos, de sorpresas violentas, de noticias absurdas» (f. 16r).

Més en concret, Oller carrega contra Joan Mañé i Flaqué, «escritor católico-apostólico-romano al estilo de Mont[a]lambert, Veuillot, Gratry en Francia», l'enterrament del qual imagina (ff. 8-11). Hi havia polemitzat sobre la necessitat de reformar la Rambla, respecte a la qual es remarca que, tot i ser «la via principal i más concurrida» (amb el Teatre Principal, que «ocupaba parte del actual Gran Hotel de Ambos Mundos», i el Liceu, «que abarcaba una parte de los Grandes Almacenes de la Compañía Universal»), a començament del segle XIX «era un arenal y casi a fines del mismo estaría tan despoblada aún que servía de paseo y de mercado para la venta al aire libre de aves, gallinas, conejos y demás artículos de primera necesidad, con poquito de comercio de flores»; «por su arroyo, hoy intransitable, a pesar de su mayor anchura, discurrían contados coches, jardineras y tramvías», encara «movidos por tracción animal» (ff. 12-13) ${ }^{24}$. Envoltaven la Rambla els barris 1, 2 i 3

23 «Duración e influencia» a l'interlineat, dalt d' «influencia y prestigio», ratllats.

24 S'ha ratllat l'adjectiu «pequeña» que qualificava la part del Liceu compresa dins los Grandes Almacenes i s'ha escrit «actual» a l'interlineat, dalt de «gran». Després de «Principal» s'ha guixat, successivament, «que ocu» i, a la interlínia, «y el Liceo». Sembla, doncs, que Oller, va optar per reprendre el primer redactat. S'ha afegit a llapis «y no sé si ya también los pesados automóviles», escrivint aquesta paraula amb $b$, primer a la interlínia, dalt d' «as y tramvias todos», on s'ha ratllat tot l'afegitó, i després al marge superior del full següent. A l'interlineat, s'ha escrit «rieles», dalt de «railes», guixat. Sobre la controvèrsia amb Mañé, veg. particularment Cabré 2004: 48-49, 168-179 i 210-214, llibre al qual em remeto també pel que fa a la visió olleriana d'al- 
del Cuartel Marítimo, «verdaderos dédalos de callejas inmundas y aterrador vivero de microbios que diezmaban la población sin descanso» (f. 13). En contrast, els moderns «aerostáticos de 100 plazas» «conducen hasta media noche a los cuarteles campestres de $\mathrm{N}$ y $\mathrm{O} »$ - al.ludint amb les inicials dels punts cardinals les seves- i «electrotrenes» comuniquen «los demás barrios» $(\text { f. } 16 r)^{25}$.

Es caricatura també l'Exposició Universal de 1888, en què, dins les reduïdes dimensions del recinte (ubicat a l' «square de Oriente», que «subsistió mucho tiempo con el ridículo nombre de Parque»), es van acumular «centenares de telas pintadas y trastos viejos con los bastos productos de sus atrasadas industrias», dels quals, tanmateix, els avis n'estaven «ufanísimos» (ff. 13-14) ${ }^{26}$. Més en general, es contraposa, a grans trets, el segle XIX al XX:

Aquel era el siglo del vapor y este, el de la electricidad y de los gases explosivos; aquel el siglo de las guerras y este, el de la paz; aquel el de la pasión y la disputa eterna y este, el de la experimentación y de la verdad científica; aquel el de la política utópica y deletérea y este, el de la administración práctica; aquel, siglo de lágrimas y de duda; este, siglo de alegrías y de luz. (ff. 3-4) 27 $^{27}$

Descartats aquests textos, encara que potser acceptat algun altre d'Oller, en el suplement de La Vanguardia, s'inclou, com a fulletó, l'inici de la novel-la «La selección infinita» (pp. [5]-6), l'argument de la qual no se situa en cap època concreta, però les seves característiques i el context suggereixen que l'ambientació és contemporània respecte a la data apòcrifa. L'anunci de la continuació sembla que respon tan sols a la parodia dels lliuraments, procediment pel qual el diari publicava aleshores Siska van Roosemael, de Hendrik Conscience, també com a fulletó.

El títol de «La selección infinita» suggereix el darwinisme i ho corrobora el nom del pretès autor: «Hipócrates Darwin». El pseudònim fa pensar que podria amagar algun metge, però podria obeir només a la voluntat de parodiar el cientisme ${ }^{28}$. D'altra banda, l'obra podria haver estat redactada col-lectivament. Val a recordar que el pseudònim evolucionista té un precedent amb el de $\ll$ F. de Lamarch» o «Lamark» (evocant Jean-Baptiste Pierre Antoine de Monet de Lamarck), que ha estat adjudicat a Valentí Almirall, Pompeu Gener i Josep

tres aspectes urbanístics barcelonins. Sobre la representació de Barcelona en la literatura catalana, veg., particularment, Casacuberta + Gustà 2008

25 El terme electroscopo s'utilitzava a vegades també amb el sentit d'electroscopio.

26 «Bastos» escrit a l'interlineat, dalt de la paraula ratllada «rústicos».

27 «Duda» és escrit a l'interlínia dalt de la paraula guixada «lucha».

28 Entre els col-laboradors de La Vanguardia aleshores es troba el Dr. Francesc de Paula Xercavins i Rius (Calbet + Montañà 2001: 198). El comentari que «un novelista soltero» no «podrá soñar»l' «escena de alcoba» narrada, «que puede describir todo casado observador» (11. 122-123), no ha d'implicar l'estat civil de l'autor real. El pseudònim s'afegeix als que figuren en diversos repertoris,com Manent + Poca 2013. 
Narcís Roca i Ferreras. He aportat, però, un exemplar de La Provincia. Periódico Republicano Federalista amb una col-laboració signada «F. de Lamark» atribuïda a mà a «Felip de Saleta [i Cruixent]», identificació que he corroborat amb altres arguments (Vall 2010: 16).

Cal remarcar que Pompeu Gener era aleshores un dels assidus collaboradors de La Vanguardia, encara que no figura entre els participants en la innocentada enumerats per Rahola a Rusiñol en la carta del 10 de desembre ${ }^{29}$. De totes maneres, encara devia ser a París, perquè hi data 9 dies després un article (Gener 1889b) publicat en El Barcelonés sobre l' «Epidemia reciente», en què informa que «Estaba haciendo mis baúles cuando me cogió el dengue, o lo que sea, y no tuve más remedio que meterme en cama y hasta hoy no he podido levantarme a causa de la fiebre». Per aquest motiu, no havia pogut tornar a Barcelona per retre compte de la missió encarregada per l'Ajuntament a l'Exposició Universal, de la qual ja havia enviat diverses cròniques. A la capital francesa estava en contacte amb Rusiñol i Utrillo, com prova un article d'aquest del 20 de novembre donant notícia de la proposta a Gener d'una càtedra a Xile (Utrillo 1889).

Gener assegurava haver-se doctorat en medicina a París, encara que, com suggereix Apel-les Mestres, podria ser una de les seves invencions, perquè no se'n localitza documentació fefaent ni al seu fons ni en aquella ciutat (Vall 2008: 314). Com és prou conegut, va escriure narracions fantàstiques, algunes recollides a antologies. Ja m'he ocupat, tangencialment, d'aquest aspecte i, més plenament, de la seva actitud vers l'evolucionisme, de la seva oposició a l'aplicació literària que en va fer el naturalisme i, particularment, a la figura del struggleforlifer, i de la seva defensa d'un autor citat en la novel-la, Stendhal $(\text { Vall 2008) })^{30}$.

Curiosament, el número de l'ascensor de «La selección infinita», el 35, coincideix amb el de la «Fantasía futurista» «El Theological Palace» (Gener [1912]: 282), a diferència de la versió catalana (Vall 2008: 317, 335), en què és el 21. D'altra banda, aquest autor, tot i que la seva valoració de les dones és més complexa, manifesta, com la narració de La Vanguardia, una considerable misogínia, entre altres escrits, en una de les col-laboracions recents d'aquest diari (Gener 1889a). Menys prudentment, sovint s'han atribuït, sense ni dubtar, obres basant-se amb coincidències més escasses. En tot cas, les «Noticias locales» deuen al-ludir Gener, juntament amb Joan Salas Anton, en la figura del «joven anticuario» Gésar Gener y de Salas Antón, que prova a l'Acadèmia de

29 Ambdós assistien a les tertúlies del «Cau Ferrat» (Clarasó 1931: 14, 60-61). El 1881, quan Gener era secretari de l'Ateneu Barcelonès i Rahola vicesecretari, aquest va escriure una ressenya del llibre La mort et le diable: «L'obra d'en Pomeyo Gener segons la prempsa extrangera», La Llumanera de Nova York, 70 (febrer 1881), pp. 2-3. Es conserven algunes cartes seves al fons de Pompeu Gener de l'Arxiu Històric de la Ciutat de Barcelona (capsa 10), en el qual no he localitzat cap notícia d'aquesta innocentada.

30 En un estudi sobre les col-laboracions periodístiques franceses de Gener, ja comentaré l'article anònim «Darwinisme littéraire», Le Télégraphe, 14-5-1885, pp. 1-2, publicat en un diari en què evoca haver col-laborat i integrat, com a propi, en els seus escrits castellans sobre el tema. 
Bones Lletres que unes ruïnes corresponen a una «cerca» per reparar la torre romana adossada al Palau Episcopal (p. 8) ${ }^{31}$.

També col-laborava aleshores en La Vanguardia i s'esmenta en la llista de Rahola, Joan Sardà, que, en un article de La Renaixensa, havia parodiat el cientisme de manera que recorda Frankenstein (Sardà 1875, Tayadella 1997: 14, Vall 2005: 14). Dies abans de la innocentada, a propòsit de les actuacions de «Buffalo Bill» a Barcelona (Marill 1998), també havia criticat «el mito del progreso» darwinista:

La gran camama de la historia del mundo, viene sacrificando razas y pueblos desde que la tierra es tierra, y la especie fuerte va saciando la fatal voracidad de sus apetitos colectivos con los despojos de las especies menos fuertes. El hombre blanco, o mejor, la humanidad blanca es realmente la reina de la creación terrestre, pero reina a cuyos festines han da traer sus carnes todos los demás seres del reino animal. El filósofo de corazón se siente aterrorizado ante esa ley que va sacrificando a las fatalidades de la naturaleza el bienestar de millones de individuos para quienes, a pesar de ser negros, amarillos o cobrizos, también es patria el pedazo de tierra en que vivieron sus abuelos. (Sardà 1889)

«La selección infinita» respon poc a les expectatives darwinistes, atès que planteja convencionalment la tòpica rivalitat entre una noia, Paz, i la seva madrastra, Emma, que no aconsegueix apaivagar el pare de la primera i marit de la segona, Nicomedes (etimològicament, 'el que procura la victòria') Pujol, director d'una fàbrica d'explosius. Amb reminiscències de la teoria dels humors, se'l defineix com a «linfático» (1. 50), mentre que la filla, lluny d'heretar aquest caràcter, és «sanguíneo-biliosa» (1. 166). Arran d'aquests conflictes, Paz, que tampoc fa honor al nom, dictamina: «Donde no hay solidarismo, hay que provocar la eliminación» (1. 236), amb l'aprovació de l'abatut Nicomedes. Es combina així, grotescament, la selecció, artificial, amb la cooperació ${ }^{32}$. Similarment, si bé en un sentit més general i a propòsit de la revolució russa, en Fabra 1889: 335, se sentencia: «Todo obedece a la eterna ley de la evolución». En «La selección infinita», es planteja, a més, l'eugenèsia argüint que els caràcters oposats dels pares enforteixen els descendents (11. 75-78).

Uns dies després de la innocentada, el 12 de gener, el diari va publicar, també en forma de fulletó, les cartes jocoses d'Ángel a la seva cosina Panchita, obra de l'escriptor mallorquí Bartomeu Amengual (1890). En una, datada el 25 de desembre de 1889, havent confirmat el protagonista que ella s'embriaga amb nafta, imagina que els fills seran «quinques con mecha y tubo», segons li han suggerit, «indudablemente», les teories de Darwin. M'ocupo de

31 El diari havia donat notícia de l'inici d'aquestes obres el 23 d'agost (1046, p. 1).

32 De totes maneres, Darwin i el darwinisme han intentat conciliar «la lluita per la vida» amb l'altruisme, com han ressaltat diversos estudis. 
la recepció de l'evolucionisme en la literatura catalana en un article en curs de publicació.

El fil conductor d'un feble argument protagonitzat per una família burgesa i el començament de «La selección infinita» recorden força la narració de Robida (1883: 1-6), en què les dues filles i una neboda d'un banquer arriben a l'estació amb un globus aerostàtic, amb forma de peix. Fins i tot hi fan pensar detalls com l'esmorteïment de l'aterratge $\mathrm{i}$ els ascensors.

És especialment interessant la concepció, si bé caricaturesca, de la Barcelona futura, en la mesura que ho afavoreix l'itinerari dels personatges. D. Nicomedes i la muller es desplacen des del bulevar Montjuïc, passant per la plaça de «Francia Chica» — que deu inspirar-se en la de Catalunya, com corrobora la referència al Circ Eqüestre—33, fins a l'Estació Universal (aquest mateix adjectiu porta la companyia ferroviària de Fabra 1889: 338), ubicada davant la plaça del Segle XX i amb vistes al mar, la qual suggereix la de França. La noia arriba de l'«Imperio Argentino» (sembla que amb intenció d'al-ludir Fabra 1889, si bé en Robida 1883: 180-183 s'havia narrat ja un viatge a Argentina), passant per Panamà (des d'on, en Robida 1883: 283, sortia un «tube transatlantique» cap a Brest) i pel Cap Verd. Els tres personatges emboquen per la Diagonal la Gran Via fins a Sant Boi, on D. Nicomedes té la casa i la fàbrica.

Els mitjans de transport són sovint de tracció animal o s'animalitzen. Els personatges es desplacen per la ciutat amb una «lujosa araña» (terme sinònim de buggy) i un «carruaje de junco volcanizado» amb un «tronco», 'conjunto de dos o más mulas o caballos que tiran de un carruaje' (Diccionario de la lengua española de la RAE,), que trota, si bé sense fatiga, i també «vola», almenys en sentit figurat (11. 1-4, 14-16 i 112-113). Els trens aeris internacionals són «águilas», encara que de cautxú, que mouen immenses ales «llenas de viento» $\mathrm{i}$ tenen rodes d'aterratge (11. 33-35). Els aeròstats dels «servicio interior» porten els passatgers en cistelles «aleteando como monstruosos murciélagos» (1l. 103-109).

La novel-la, com el suplement en conjunt, amb l'estímul de diversos referents literaris i no sense ironia, respon al cofoisme vuitcentista envers els avenços tecnològics coetanis i les expectatives de progrés moral. Té una certa gràcia que, mentre que la tecnologia ha avançat molt més que no preveien, lluny d'haver-se aconseguit que els equipatges siguin enviats a casa (1. 99), se solen perdre i els clergues de la religió més estesa a Barcelona no tan sols no es poden divorciar (11. 189-190), sinó tampoc casar.

Sense més preàmbuls, n'edito el text, regularizant-ne, com he fet en les citacions, la puntuació, l'accentuació i altres aspectes ortogràfics (detallo els de la narració a l'acabament). Convé no oblidar que la normativa de l'època no coincideix plenament amb l'actual.

33 En l'article «A través de un siglo», s'ironitza sobre l'acumulació a la plaça de tota mena d'atraccions (p. 6). 


\title{
LA SELECCIÓN INFINITA
}

\author{
Novela original de Hipócrates Darwin
}

45 minutos hacía que venían, arrellanados en los muelles cojines de su lujosa araña, el opulento director de Materiales Explosivos y Emma, su actual pareja, cuando el brioso tronco que arrastraba sin fatiga aquel hermoso carruaje de junco vulcanizado emprendió trotando la suave cuesta del bulevar Montjuïc.

$5 \quad$ En 2 minutos, 5 segundos, dejaron atrás la extensa verja del square de Francia Chica, discurrieron luego a lo largo de los suntuosos hoteles allí alineados, galoparon sin pena entre la baraúnda de carruajes que iban y venían del Circo Hípico y desembocaron, al fin, en la grandiosa plaza del Siglo XX, atestada asimismo de carruajes de toda índole.

10 Se acercaba la hora. La bandada o tren de aeróstatos ultramarinos iba a llegar de un momento a otro. Su débil perfil se dibujaba ya en la violácea cerrazón del horizonte, a algunas brazas sobre el azul del mar. Dos minutos más y entrarían en la estación. ¡Cómo que ya solo distaban unas diez millas!

La araña del director de Materiales Explosivos sorteó como pudo el hormi-

15 gueo de la plaza, aprovechando un claro de la extensísima fila de carruajes que se alineaban al pie de la Estación Universal. Paró para que bajaran sus dueños.

Emma y su hombre, D. Nicomedes, saltaron del estribo. Penetraron en la estación por la puerta 36. A 52 metros sobre sus cabezas, tendíanse dentro de la vasta nave 20 pares de rieles, sobre los que debían rodar los aeróstatos

20500 metros para enfrenar su empuje. 30 metros más arriba, brillaba la cubierta de cristal a los últimos rayos del sol muriente de aquella tarde de otoño, mas pronto la claridad de 40 focos eléctricos de 1.000 bujías sofocó aquellas melancólicas postrimerías de luz solar.

Un repiqueteo de campanas eléctricas cien veces multiplicado respondió al 25 enorme bramido de sirena que conmovió los espacios. Factores y jefes de estación removiéronse en los altos andenes. Emma y D. Nicomedes levantaron, como todo el mundo, la cabeza en dirección del sud. Y vieron avanzar como relámpago la enorme hilera de monstruosas águilas que batían perezosamente sus enormes alas de, metros, 20,05, llenas de viento, como velas latinas que 30 embisten el puerto.

Retumbó estridente estruendo de cadenas; un soplo de huracán derribó los sombreros de los mal precavidos espectadores. El tren entraba en la estación. Los aeróstatos plegaban las alas, encajaban en los camastrones rodados y las ruedas volaban silbando sobre los rieles a que estaban sujetas, lanzando extensas ráfagas 35 de doradas chispas. El tren paró. Abriéronse las portezuelas de las enormes águi- 
las de cauchout, interiormente iluminadas de fosforescente luz, y cayeron enseguida en el andén bajo millares de listas impresas, que la multitud se arrebataba. D. Nicomedes recorrió la lista sin pestañear hasta dar con el grupo letra P.

-Aquí estará, dijo para su capote, que era hoy un luenguísimo pardessus.

— «Paz Pujol» —leyó en alta voz en el nº 83 de la P— «Águila 10, descenso: ascensor $35 »$.

Plegó la lista, cogió a Emma del brazo y dirigiose corriendo al ascensor 35, distante de allí, metros, 305,49.

La trepidación de los 523 viajeros que desbuchaban las águilas sobre eleva-

45 dos andenes, la caída de los mundos y universos que arrojaban a ellos los factores, el rechinar de los ascensores, que bajaban a los recién llegados y subían a las multitudes de pasajeros del interior, movían alegre rumor de vida dentro de aquella vasta nave de cristal y acero cuyo cruce de arcos se perdía en la vaguedad de las alturas.

50 D. Nicomedes, que era un patilludo linfático y obeso — como convenía a su alta posición civil-, llegó al ascensor bufando y más encendido que cresta de gallo. Emma le había seguido con pena hasta que se decidió a desabrocharse el pardessus, con el cual tropezaba a cada instante, y pudo ceñirse mejor el pantalón bombacho metiéndose ambas manos en las faltriqueras. Pero, peor aun, mil

55 veces peor que esas molestias físicas, era el mal humor que llevaba en el alma. Emma había ido allí a la fuerza. Celosa como leona, no podía ni tolerar la presencia de su rival, de la hija de su esposo. ¿Cómo, pues, se había dejado arrastrar hasta allí para saludarla en el momento de llegar? D. Nicomedes la había engañado. Soñaba en reconciliaciones imposibles. Emma estaba furiosa.

60 Paz Pujol, sin embargo, saltó de la puerta del ascensor al cuello de su papá y apretó luego con brusca sacudida la mano de Emma, sustituta de su madre en el domicilio paterno. Aquel apretón encerraba toda una historia, un drama horrible, el nublado de una tempestad tremenda pronta a estallar.

— ¿Cómo has dejado a tu madre? — preguntó D. Nicomedes, movido de

65 nuevas ilusiones que hacia su primera mujer hacía relampaguear en él la dilatada ausencia.

—Buena, muy bien — contestó la chica, no sin retintín.

— ¿Está contenta con don Facundo?

-A partir un piñón.

70 Emma, cada vez más impaciente, saludó con cara de vinagre, en vez de sonreír, a una amiga que acertaba a cruzar junto a ella.

—Y... ¿Qué tal? ¿No hay anuncios de sucesión? — continuó preguntando don Nicomedes, como si se empeñara en amontonar imprudencias.

Emma le pellizcó el brazo fuertemente. 
$75-$ No, ni, fisiológicamente hablando, es probable —respondió la doncella-. Hay entre los dos harta afinidad de temperamentos.

—Mejor así —opuso el padre—. Débil sería el fruto. Y... ¿Cuándo salisteis de allí? ¿A las 3.25 o a las 3.30?

— ¿De Panamá? A las 3.33 de anteayer.

$80-$ Me lo figuraba, porque traía un retardo de 7 minutos, 33 segundos. ¿Habéis tenido algún temporal?

—Sí, lo había sobre el Cabo Verde; pero nos hemos elevado a 8.000 metros $\mathrm{y}$ hemos dejado que rugiera el trueno a nuestros pies.

85 melindre.

—Y... ¿No se ha mareado usted? — preguntó Emma con afectado y procaz

— Se me figura que no — contestó la chica, desafiándola con la mirada.

— ¿Has, por fin, firmado la escritura? — prosiguió don Nicomedes sin notar siquiera los relámpagos de la tempestad que se acercaba por segundos.

-15 minutos antes de partir de allí.

$90-$ - Y.. ¿ Traes el dinero?

— ¡Ya lo creo! 20.000 pesos, aquí en la cartera —afirmó la muchacha golpeándose el pecho izquierdo para indicar el bolso interior de su ajustada túnica.

Y luego, abriéndose más el pardessus y echándose el hongo hacia atrás, volvió a arrojarse en brazos de su padre, más procaz que nunca, mientras

95 Emma, con estudiado disimulo, se interponía entre los dos rápidamente.

Los ojos de entrambas damas disparaban chispas, que se cruzaron como saetas. Pero el bueno de don Nicomedes hizo la vista gorda, selló las dos frentes con un beso y, con aire bonachón, continuó preguntando a su hija si traía el equipaje facturado a domicilio.

100 -Sí, papá.

—Vamos, pues — concluyó el buen señor- Ya lo llevaran a casa. La araña nos espera a la puerta.

En aquel instante bramaron hórridamente 4 sirenas y viose salir de las alturas, aleteando como monstruosos murciélagos, otros tantos aeróstatos, que

105 se dispersaron por los 4 puntos cardinales de la ciudad, llevando en doradas cestas espléndidamente iluminadas multitud de pasajeros, que asomaban sus cabecitas al bordillo para contemplar el panorama de Barcelona, que, allá en las profundidades, huía, vago y refulgente a la vez. Eran aeróstatos del servicio interior.

\section{II}

110 Don Nicomedes Pujol habitaba un hermoso pabellón situado dentro de la inmensa área que ocupaban los talleres y laboratorios de la sociedad por él dirigida, barrio de San Baudilio, muelle del Llobregat, número 1203. La araña, que 
por la Diagonal tomó la Gran Vía, llegó allí en 15 minutos. Un portero, negro de raza, verde de cascos y azul de librea, abrió la ancha verja de níquel y la araña

115 penetró volando por las tortuosas avenidas del parque, hasta dar con la luciente escalinata donde se aperaron los señores. Emma tomó el brazo de don Nicomedes, y Paz les precedió, no parando hasta su camarín.

$/ /{ }^{6}$ Era, este, un hermoso gabinete, tapizado de fosforescentes telas que, a un ligero movimiento del conmutador, despedían una claridad difusa y brillante

120 como el sol. Emma tiró sobre su cama de bronce dorado el pardessus y el sombrero, contemplo su biblioteca, su teléfono, su fonógrafo, su teléfoto, su velador y soltó un suspiro de satisfacción. Todo estaba cual lo dejó hace ocho días, antes de emprender su viaje al Imperio Argentino. Volvía a estar en su casa, más dispuesta que nunca a acabar con aquella situación insostenible. ¡Oh, sí, estaba

125 resuelta a todo, al mayor de los sacrificios! Ella amaba a su padre. Quería liberarle de la garras de aquella hiena que le estaba devorando, prepararle una vejez grata, apacible, como merecían sus virtudes. ¡Pobre papá!

Pero la muchacha sintió frío y, malhumorada y pensativa, tendiose en la chaise longue, abriendo antes la espita contigua. Un vapor cálido e impalpable

130 inundó la atmósfera hasta dejarla a la temperatura de $19^{\circ}$ centígrados.

Paz se disponía a meditar; pero ¿cómo meditar si oyó voces de disputa?

— ¡Ah, cruel! ¡Ah, vampiro infernal!

Y, como movida de extraño resorte, saltó de allí y, a hurtadillas, llegose hasta el umbral del gabinete de don Nicomedes y, tras el portier, escuchó.

135 La escena era violentísima, terrible, escena de alcoba de esas que nunca podrá soñar un novelista soltero y que puede describir todo casado observador, escena de esas que hacen sospechar de la verdad de las Escrituras cuando suponen que hubo en el Paraíso más culebra que la mujer, como si la mujer mala necesitase sugestiones de Satán en forma de culebra. Stendhal lo dijo: Grattez

140 bien une femme; vous y trouverez toujours une vipère. Sí, una víbora hermosa, seductora, de abundante y fina cabellera como la serpiente de cascabel, pero culebra, víbora venenosa que mata, si no de un mordisco, son sus falaces caricias.

¡Ah, cuanta razón tenía Stendhal! Emma aquella noche era la culebra vene-

145 nosa. Vedla con sus piernas enroscadas a las patas del sillón de terciopelo azul en que dejose caer poco ha, suelto el pelo a las espaldas como uno de esos ángeles adultos de los pintores del siglo XIX, la ira en los ojos, en la afilada nariz, en los contraídos labios y en el color de su faz, las manos crispadas en el terciopelo, su pecho anhelante, su busto todo (aquel busto hermoso que encen-

150 dió en amor a D. Nicomedes) inclinado hacia delante en ademán de acometer... ¡Vedla despojada de atavíos y actitudes pudorosas, de disimulaciones e hipocresías...! Vedla tal cual es y retrocederéis de espanto. 
De espanto, había retrocedido el confiado marido cuando, ya en mangas de camisa y a punto de cambiarse la corbata, como solía al llegar a casa, oyola 155 proferir estas palabras:

— ¡Basta ya! ¡No aguanto más! O ella o yo.

— ¿Ella? ¿Quién? ¿Quién es ella? —osó aún preguntar aquel preguntón sempiterno que, siempre esclavo de su ciego optimismo, no había visto todavía el estado de extraordinario excitación de aquella mujer engañosa.

160

-Paz, tu hija.

A D. Nicomedes se le cayó el cielo encima. Miró y quedó espantado. Animoso como era el director de Materiales Explosivos, que jamás temió una explosión, optó no obstante por callar y recibir impasible el aluvión de injurias que vomitaba aquella culebra. Optó por no contradecirla y prosiguió su toilette 165 a alguna mayor distancia.

Pero Paz, que no era linfática como su padre, sino sanguíneo-biliosa, y que se oyó maltratada y vilipendiada por aquella boca de infierno, no pudo más; no quiso permanecer más allí. La sangre la ahogaba, la bilis se le subía a los ojos, el odio, la ira, la voz de la venganza rugían en su corazón.

— ¡Venganza...! ¡Venganza...! — gritaba dentro de sí una voz cavernosa.

Y Paz abandonó su escondite y volvió a su cuarto y abrió su secrétaire y removió todos sus cajones y llamó por teléfono al secretario de la Compañía, al mayordomo, a los criados, a los vigilantes nocturnos, al alcalde de barrio y a la policía.

Por fin, D. Nicomedes salió también de madre. No pudiendo ya más, acercose a su querida Emma y, con voz suplicante, replicó:

-Emma, por las fuerzas explosivas que más caras me son, deja a Paz en paz y no me muevas guerra.

-Te equivocas: estoy resuelta. Si quieres paz en casa, arrójala de ella. Ella aquí, es la guerra. Y la tendrás incesante y cruenta hasta que ella o yo sucumba-

180 mos, porque la provocaré a desafío y nos batiremos. Sí, nos batiremos, si ella no es tan miserable que se deje cruzar impunemente la cara en público por estos dedos que natura me dio.

- ¡Emma, por la acción propagativa! ¿Qué te ha hecho mi hija? Qué puedes decir de esa criatura que, por no dejar tú que yo lo hiciera, acaba ella de hacer

185 un viaje a América por mí, que, cuando no está en el escritorio apoyada en su mayor...

-Pues esto: lo que no quiero, que se pasa la vida contigo. Cásala con el clérigo, con ese ciego que la quiere; quítamela de casa y listos.

-No, ella no quiere al clérigo y yo se lo alabo. Tú sabes que los clérigos no

190 pueden divorciarse y yo no quiero forzarla a entrar en una esclavitud perpetua como la que padecían nuestra abuelas. ¿Te casarías tú bajo aquella amenaza...? ¡Callas...! Pues ya lo ves: mi hija no es de peor condición que tú para que yo la condene a cadena perpetua. Sin nuestras sabias leyes, no me caso yo. Lo hice 
una vez y tuve que divorciarme. He sido reincidente y se me figura que no ten-

195 dré paz en casa hasta que acuda otra vez al juez.

—Cuando tú quieras. ¡Sí, hoy..., hoy mismo, monigote!

— ¡Pero, por Dios prepotente! ¡Emma, por el Dios tonante! ¿Quién te ha dado este genio de los diablos?

—Tú me amenazas; tú me insultas.

200 -No te amenazo, no te insulto; pero advierte que, con tus celos ridículos, absurdos, increíbles, me pones en el disparadero.

- Pues yo no he de recibir cruzada de brazos tus disparos ni los de nadie. El mutuo consenso está en la ley. Tengo garantida la indemnización. Si tú prefieres a tu hija, si estás cansado de mí, el camino está expedito: mañana comparece-

205 mos ante el juez y me voy.

- No - gritó con estridente voz Paz, abriendo de par en par la puerta y apareciendo rodeada de un ejército de testigos-. No, porque esta solución sería un premio para ti, malvada mujer que estás matando a mi padre, que te has atrevido a dudar de su honradez y de la mía. No y mil veces no.

210 -Hija, hija mía, ¿qué pretendes? —exclamó el padre corriendo hacia ella.

- iSalvarte, padre mío! Salvarte de ese vampiro que te paga tus favores chupándote la sangre, llenando de infamia y de deshonra esta casa.

-Emma, aterrorizada, se había levantado y, enhiesto el cabello, arrimada a la pared, lívida la tez, los ojos despidiendo lumbre como gato acorralado, se

215 moría de miedo y de coraje, sin osar a proferir una palabra ante aquella vengadora sublime y horrible a un tiempo.

— ¡Pero, hija! ¡Oh nitrógeno puro! Pero, hija, ¿qué intentas? —preguntó el pobre D. Nicomedes con acento febril.

-Mira.

220 Y en un abrir y cerrar de ojos sacó del bolsillo un acumulador fulminante, dispuesta a soltar contra Emma un rayo mortífero, pero D. Nicomedes se interpuso entre la víctima y Paz y esta no disparó. Todos los circunstantes se arremolinaron en redor de Emma. Esta soltó un grito de terror y cayó exánime en brazos del secretario, quien la asió fuertemente contra su pecho y levantándola en

225 vilo, echó a correr.

Los testigos todos contemplaron boquiabiertos el inesperado rapto. D. Nicomedes cayó desmayado en un sillón, en tanto que Paz, su hija, que había previsto el suceso, Paz, sonrió fríamente.

- Hela aquí, padre mío, hela aquí la causa secreta de nuestras desventuras, 230 de los fingidos celos, de tus infortunios. Emma y tu secretario se amaban. Yo lo sabía. Nada me sorprende. Esta fuga yo la esperaba. Con ella, liberan tu garantía, facilitan el divorcio sin indemnización. No lo deplores, no, padre mió; yo te he salvado. ¿Verdad, testigos? 
—Sí — respondieron en coro.

235 - ¡Hija! ¡Hija de mi corazón, eres una mujer sublime!

—Donde no hay solidarismo hay que provocar la eliminación, replicó Paz con el aplomo de un sabio.

D. Nicomedes abrió los ojos con asombro, reflexionó un momento y, dándose al fin una palmada en la frente, exclamó:

240 - iQué gran verdad!

Pero enseguida le sobrecogió deplorable abatimiento.

(Se continuará)

3 carruaje] carruage. Escric amb j també bugía, gefes, viageros, viage, pasageros, muger $i$ fingidos.

4 vulcanizado] volcanizado

bulevar] bulevard

Montjuïc] Montjuic

9 asimismo] asi mismo

13 unas] una

18 puerta] puer.

29 metros] ms. A vegades, la unitat precedeix la xifra, remarcant el mesurament.

31 estruendo] extruendo

36 cauchout] No vario aquesta forma usual, encara que no normativa, del mot d'origen quetxua caucho, la qual s'acosta a la catalana cautxú $i$ a la francesa caoutchouc.

43 metros] mts.

113 Diagonal] diagonal

Gran Vía] Gran-vía

114 níquel] nikel. La k prové de la paraula alemanya nickel.

119 movimiento] mavimiento

121 teléfoto] teléfote.

129 chaise] chaisse

130 centígrados] centígrado. La forma en singular, emprada també en l'article de Rusiñol, és menys usual.

133 hurtadillas] hurtadilla. Aquesta expressió se sol utilitzar en plural, encara que també es documenta en singular. 
139 Stendhal] Standal

Grattez] gratez

144 Stendhal] Stendal

151 pudorosas] pudurosas

171 secrétaire] secretaire

182 natura] Natura

212 chupándote] chepándote

226 boquiabiertos] boqui-abiertos

\section{BIBLIOGRAFIA CONSULTADA}

Alas, L. (1886) «Cuento futuro», La Opinión, 7 i 16 (24 agost i 3 de setembre). Recollit a les Obras completas, III, Oviedo, Noble, 2003, pp. 457-478.

Almirall, V. [amb el conegut pseudònim de «Thales»] (1880) «Un manuscrit de sabi o de boix», Diari Català, 490 (16 de desembre), pp. 604-605. Recollit a V. Almirall (1985) Cultura i societat (a cura de Josep M. Figueres), Barcelona, Edicions 62, pp. 111-115.

Amengual, B. (1890) «La borrachera elegante (Cartas a un prima)», La Vanguardia, 1298 (12 de gener), p. 1.

Beraldi, H. (1916) Un caricaturiste prohète. La guerre telle qu'elle est. Prevue par A. Robida il y a trente-trois ans, París, Dorbon-Ainé <http://archive. org/details/uncaricaturistep00robiuoft $>$. [Tots els enllaços s'han comprovat el 22-2-2013].

Cabré, R. (2004) La Barcelona de Narcís Oller. Realitat i somni de la ciutat. Estudi i edició de textos (epíleg de Carola Duran), Valls, Cossetània.

Calbet i Camarasa, J. M. + Montañà i Buchaca, D. (2001) Metges i farmacèutics catalanistes (1880-1906), Valls, Cossetània.

Camprubí, X. (2011) «El valencià que inventà la màquina del temps», El Temps, 1401 (19 d'abril), pp. 80-82.

Casacuberta, M. (1993) Santiago Rusiñol. Vida, literatura i mite (dir J. Castellanos), tesi doctoral, UAB.

- (1996) «El mite de l'humor russinyolià», De Rusiñol a Monzó. L'humor i la literatura, Barcelona, Publicacions de l'Abadia de Montserrat, pp. 29-48.

- (1997) Santiago Rusiñol. Vida, literatura i mite, Barcelona, Curial / Publicacions de l'Abadia de Montserrat.

- (2002) «Retrat de la literatura catalana amb París al fons. 1888-1939», París Barcelona, 1888-1937, París, Réunion des Musées Nationaux; Barcelona, Museu Picasso, 2002, pp. 27-37. 
- + Gustà, M. (ed.) (2008) Narratives urbanes. La construcció literària de Barcelona, Barcelona, Fundació Antoni Tàpies / Arxiu Històric de la Ciutat, 2008. Editat el mateix any en castellà i el 2010 en anglès per aquestes entitats.

Coll i Coll, G. (2002) Miquel Utrillo. Un personatge polifacètic, Sitges, Grup d'Estudis Sitjatans.

Evans, A. B. (1995) «The "New" Jules Verne», Science Fiction Studies, XX: 1: 65 (març), pp. 35-46 <http://www.depauw.edu/sfs/backissues/65/evans65art.htm>.

Fabra, N. (1883a) «El desastre de Inglaterra en 1910 (una página de la historia del porvenir)», La Ilustración Española y Americana, XXVII: 5 (8 de febrer), pp. 79-82.

- (1883b) «Cuatro siglos de buen gobierno (Novela de la Edad Moderna)», Ilustración Española y Americana, XXVII: 44 (30 de novembre), pp. 311314, i XXVII: 45 (8 de desembre), pp. 338-339.

Ambdós recopilats a Por los espacios imaginarios (con escalas en tierra), Madrid, Librería de F. Fe, 1985, pp. 1-19 i 35-65.

- (1889) «Un viaje a la República Argentina en 2003», La Ilustración Española y Americana, XXXIII: 21 (8 de juny), pp. 335-338. Es va recollir, canviant en el títol l'any pel segle, a Cuentos ilustrados (1895) i ha estat força reeditat.

Aquestes i altres narracions de Fabra, a més de figurar en antologies de diversos autors, han estat aplegades a Relatos de ciencia-ficción (a cura de Francisco Arellano), Madrid, La Biblioteca del Laberinto, 2006, i La guerra de España con los Estados Unidos y otros relatos (a cura de D. González Romero), Córdoba, Berinice, 2010.

Flores, A. (1863 [1853 1a ed.]) Ayer, hoy y mañana, o la fe, el vapor, la electricidad. Cuadros sociales de 1800, 1850 y 1899. Dibujados a la pluma, Madrid, Imprenta del Establecimiento de Mellado.

Fontbona, F. (2003) «Andreu Solà Vidal en la pintura del seu temps», Andreu Solà Vidal. 1863-1902. Després de l'oblit, Ripollet, Comissió promotora de l'any Solà, pp. 19-22.

Gaspar, E. (1887) El Anacronópete. Viaje a China. Metempsicosis, Barcelona, Daniel Cortezo.

Gaziel (1994) Història de la Vanguardia (1881-1936) i nou articles sobre periodisme, Barcelona, Empúries.

Gener, P. (1889a) «De la mujer y sus derechos en las sociedades modernas», La Vanguardia, 730 (26 de febrer), p. 1.

- (1889b) «La epidemia reinante», El Barcelonés, 3186 (24 de desembre), p. 1. La conclusió es publica al núm. 3191 (30-12-1889), p. 1. 
- ([1912]) «El Theological Palace. Fantasía futurista», Del presente, del pasado y del futuro. Historias, cuentos, leyendas, apólogos, fábulas, baladas, sueños, sátiras, fantasías o lo que se quiera, París, Louis-Michaud, pp. 275-285.

GICES XIX [Grupo de Investigación del Cuento Español del Siglo XIX] (2008) El cuento en la prensa periódica del siglo XIX. Semanario Pintoresco Espanyol <http://gicesxix.uab.es>. Les entrades sobre Juan Rúa Figueroa són de Teresa Barjau, segons ha tingut l'amabilitat d'informar-me'n la investigadora principal del projecte, Montserrat Amores.

Giné Janer, M. (2010) «La exposición universal de París (1889). Su recepción en La Vanguardia», La culture de l'autre. L'enseignement des langues à l'Université. Actes $<\mathrm{http}$ ://cle.ens-lyon.fr/espagnol/la-exposicion-universalde-paris-1889-su-recepcion-en-la-vanguardia-92846.kjsp>.

Huertas, J. M. (2006) Una història de «La Vanguardia», Barcelona, Angle.

Jobit, P. (1936) Les educateurs de l'Espagne contemporaine. I. Les Krausistes, París, Boccard.

Lacaze, D. (1979) «Lectures croisées de Jules Verne et de Robida», F. Raymond; S. Vierne (ed.), Jules Verne et les sciences humaines, París, Union Générale d'Éditions, pp. 76-100.

Laplana, J. de C. (1995) Santiago Rusiñol. El pintor, l'home, Barcelona, Publicacions de l'Abadia de Montserrat.

Lasa, J. F. (1996) «Fantasies del segle passat», Serra d'Or, 434 (febrer), p. 70.

Mainer (1988) «Una paráfrasis de H. G. Wells en 1909 y algunas notas sobre la fantasía científica en España», J. P. Etienvre i L. Romero (coord.), La Recepción del texto literario (coloquio Casa de Velázquez-Departamento de Filología de la Universidad de Zaragoza. Jaca, abril de 1986), Zaragoza, UZ, pp. 145-176.

Manent, A. + Poca, J. (2013) Diccionari de pseudònims usats a Catalunya i a l'emigració, Lleida, Pagès.

Marill Escudé, J. (1998) Aquell hivern... L'espectacle de Buffalo Bill a Barcelona, Palma, J. J. de Olañeta.

Martínez-Gil, V., ed. (2005) Els altres mons de la literatura catalana. Antologia de narrativa fantàstica i especulativa, Barcelona, Galàxia Gutenberg.

Moncel, T. du (1882) Le microphone, le radiophone et le phonographe, París, Librairie Hachette.

Munné-Jordà, A. (1985) «La ciència-ficció en la literatura catalana», L'Espill, 22 (octubre), pp. 25-48.

- (2002) «La literatura catalana d'especulació científica i tecnològica de la Renaixença a la Guerra Civil», Entre la por i l'esperança. Percepció de la tecnociència en la literatura i el cinema, Barcelona, Proa, pp. 69-96.

- (2005) «Jules Verne dins el nostre imaginari col-lectiu», Serra d'Or, 543 (març 2005), pp. 10-12. 
O[ller]., N. (s. a.) «Antiguallas». Arxiu Històric de la Ciutat de Barcelona, fons personal de Narcís Oller, 5D.53-8/C11-1.

- (s. a.) «El hotel de la muerte», al mateix fons, 5D.53-8/C11-2.

Panyella, V. (1981) Epistolari del Cau Ferrat. 1889-1930, Sitges, Grup d'Estudis Sitgetans.

- (2009) Miquel Utrillo i les arts, Sitges, Ajuntament / Consorci del Patrimoni.

- (2012) Santiago Rusiñol: La campanya de Poblet de 1889, Espluga de Francolí: Museu Vida Rural, 2012.

Pinyol, R. (2005) «La recepció de Verne a Catalunya», Serra d'Or, 543 (març 2005), pp. 17-20.

- (2006) «Les escriptores catalanes vuitcentistes i la traducció», Quaderns. Revista de traducció, 13 (2006), pp. 67-75.

Roas Deus, D. (2000) La recepción de la literatura fantástica en la España del siglo XIX (dir. Sergio Beser), tesis doctoral, UAB.

Robida, A. (1883) Le vingtième siècle, París, Georges Decaux <ftp://ftp.bnf. fr/574/N5746617_PDF_1_-1DM.pdf>.

Roig, S. (2012) El futur dels nostres avis, Girona, Diputació de Girona.

Rúa Figueroa, J. (1851) «Madrid en el año 2851. Nuevo porvenir del mundo», Semanario Pintoresco Español, 1 i 2 (5 i 12 de gener), pp. 6-7 i 14-15.

Rusiñol, M. (1968) Santiago Rusiñol vist per la seva filla, Barcelona, Aedos.

Rusiñol, S. (1973, 1976) Obres completes, 2 vols., Barcelona, Selecta.

Saiz Cidoncha, C. (1988) La Ciencia ficción como fenómeno de comunicación $y$ de cultura de masas en España, Madrid, UCM.

Santiáñez-Tió, N. (1995) De la Luna a Mecanópolis. Antología de la ciencia ficción española (1832-1913), Barcelona, Quaderns Crema.

S[ardà] Lloret, [J]. (1875) «La darrera paraula de la ciència», La Renaixensa, II: 20 (31 de juliol), pp. 176-179. Recollit a J. Sardà (1997) Art $i$ veritat. Crítiques de novel-la vuitcentista (a cura d'A. Tayadella), Curial, Barcelona, pp. 33-36, i reproduït en el Butlletí Electrònic de la Societat Catalana de Ciència-Ficció i Fantasia, 7 (novembre-desembre 2007).

Sardá, J. (1889) «Buffalo Bill», La Vanguardia, 1251 (15 de desembre), p. 4.

Sierra i Farreras, R. (2012) «Miquel Utrillo, cronista de "La Vanguardia" (1889-1891)», Diari de Vilanova (16 de març), p. 38.

Simón Díaz, J. (1946) Semanario pintoresco español (Madrid, 1836-1857), Madrid, Instituto "Nicolás Antonio" del CSIC.

Souvestre, E. (s. a.) Le monde tel qu'il sera, París, W. Coquebert. 
Tayadella, A. (1997) «Introducció» a J. Sardà, Art i veritat, pp. 5-23. Aplegat al recull d'estudis de l'autora Sobre literatura del segle XIX, Barcelona, UB; Vic, Societat Verdaguer, 2012, pp. 125-140.

Teruel, J. (2003) «Andreu Solà Vidal. Assaig de biografia», Andreu Solà Vidal. 1863-1902. Després de l'oblit, Ripollet, Comissió promotora de l'any Solà, 2003, pp. 55-64.

Uribe, A. (2002) «De los proto-máquinas del tiempo a las anticipaciones de lo por venir», F. Martínez de la Hidalga et al., La ciencia ficción española, Madrid, Robel, pp. 25-63.

Utrillo, M. (1889) «Cartas de París», 1214, La Vanguardia, 25 de noviembre, pp. 2-3.

Vall, X. (2005) «La ciència en la poesia catalana del segle XIX», Caplletra, 39 (tardor), pp. 9-59.

- (2008) «Pompeu Gener, un positivista darwinista contrario al naturalismo zoliano (colaboraciones en la prensa de Barcelona y Madrid)», Revista de Filología Románica, 25, pp. 313-335.

- (2010) «Aspectes de la "modernitat" al segle xix», R. Panyella (ed.), Concepcions $i$ discursos sobre la modernitat en la literatura catalana dels segles XIX $i$ XX, Lleida, Punctum.

- (2012) «The Phonograph in Barcelona (1877-1880): Thechnology and ideological controversies», Quaderns d'Història de l'Enginyeria, XIII, pp. 255-286.

Vanguardia, La (1889) «Suplemento al número 1272, correspondiente al 28 de diciembre de 1889», La Vanguardia (28 de desembre), pp. [5]-8.

- (1890) Apuntes para el resumen del año 1889. Regalo de La Vanguardia a sus sucritores, Barcelona, Tipografía de «La Vanguardia».

Verne, J. (s. a) Une ville idéale. Amiens en l'an 2000. Discours prononcé par Jules Verne à l'Académie des sciences, belles-lettres et arts d'Amiens le 12 décembre 1875 <http://www.france-pittoresque.com/spip.php?article999>

Verne, J. (1889) «El periodismo en 2889», El Isleño, 10638 (1 d'abril), pp. 1-2.

- (1995) París al segle XX (trad. Manuel Costa-Pau), Barcelona, Planeta.

- (2004) Au XXIXe siècle ou la journée d'un journaliste américain en 2889 (1889) <http://jv.gilead.org.il/ebooksgratuits/jules_verne_journee_journaliste_americain.pdf $>$

Verne, J. i M. (2011) «In the Year 2889» < http://www.gutenberg.org/ebooks/19362>.

Voltes, P. (1964) «Cómo imaginaron Rusiñol y otros humoristas que sería la Barcelona en 1989», La Vanguardia, 30498 (25 de juny), p. 27. Recollit a P. Voltes Bou (1976) Notas sobre instituciones barcelonesas del siglo XIX, Barcelona, Instituto Municipal de Historia, pp. 186-190.

Yxart, J. (1888) «Un crimen en 1988 (de un períodico futuro)», La Vanguardia, 380 (15 d'agost), p. 1. 